\begin{tabular}{|c|c|c|}
\hline & $\begin{array}{c}\text { International Journal of Current Research in } \\
\text { Biosciences and Plant Biology } \\
\text { BXCELLENT } \\
\text { PUBLISHERS }\end{array}$ \\
Volume 5 - Number 6 (June-2018) • ISSN: 2349-8080 (Online) \\
Journal homepage: www.ijcrbp.com
\end{tabular}

\title{
Mass Production of Stevia rebaudiana (Bertoni) Bertoni for Commercial Cultivation
}

\author{
D.L.C.K. Fonseka*, W.W.U.I. Wickramaarachchi and H.N. Aluthgamage
}

Department of Crop Science, Faculty of Agriculture, University of Ruhuna, Mapalana, Kamburupitiya, Sri Lanka

*Corresponding author.

\begin{tabular}{|c|c|}
\hline Article Info & ABSTRACT \\
\hline $\begin{array}{l}\text { Date of Acceptance: } \\
30 \text { May } 2018 \\
\text { Date of Publication: } \\
\text { 06 June } 2018\end{array}$ & $\begin{array}{l}\text { Stevia rebaudiana is a medicinally important herb belongs to Asteraceae family. It is } \\
\text { highly important in anti-diabetic treatments due to sweet taste with zero calorific } \\
\text { value. Stevia is a natural alternative source to traditional sugar (sucrose) obtained from } \\
\text { sugarcane and sugar beet. The aim of this research was to develop a protocol for mass } \\
\text { production of this important medicinal herb for commercialization. The experiments }\end{array}$ \\
\hline Keywords & for the mass propagation of \\
\hline $\begin{array}{l}\text { Acclimatization } \\
\text { Coco-pellet } \\
\text { Nodal explants } \\
\text { Proliferation } \\
\text { Shoot tip explants } \\
\text { Stevia rebaudiana }\end{array}$ & $\begin{array}{l}\text { Design (CRD). Explants were collected from } 10 \text { weeks old mother plants maintained in } \\
\text { shade house conditions. Surface sterilized explants were cultured on MS (Murashiege } \\
\text { and Skoog) medium for culture establishment. Established shoot tips and nodal } \\
\text { segment explants were transferred to MS medium containing different concentrations } \\
\text { and combinations of BAP, Kinetin and NAA. The highest plantlet proliferation was } \\
\text { observed in the MS medium supplemented with } 0.2 \mathrm{mg} / \mathrm{L} \text { NAA, } 0.5 \mathrm{mg} / \mathrm{L} \text { BAP and } 1 \\
\mathrm{mg} / \mathrm{L} \text { Kinetin after } 6^{\text {th }} \text { week of ex-plant establishment. Rooting was observed in the MS } \\
\text { medium supplemented with } 0.5 \mathrm{mg} \mathrm{L}^{-1} \text { of IBA and } 0.2 \mathrm{mg} \mathrm{L}^{-1} \mathrm{IAA} \text { leading to a } \\
\text { successful plantlet regeneration with well-developed shoots and roots that are ready } \\
\text { for acclimatization. Highest survival percentage }(90 \%) \text { was observed using coco-pellet } \\
\text { as a substrate under high humid conditions. }\end{array}$ \\
\hline
\end{tabular}

\section{Introduction}

Stevia rebaudiana is a member of the family Asteraceae, which is popularly known as Stevia, is a natural alternative source to traditional sugar (sucrose) obtained from sugarcane and sugar beet. Recently, S. rebaudiana has received a greater attention due to its high range of sweet content with zero calorific value and its therapeutic importance for inhibiting fat accumulation and lowering blood pressure (Soejarto et al., 1982). The leaves of Stevia composed of diterpene glycosides, such as stevioside and rebaudiosides (Tanaka, 1982). Pure extract of stevioside is non-caloric and 300 times 
sweeter than sugar (Bhosle, 2004)unlike many lowcaloric sweeteners, stevioside is stable at high temperatures and over a range of $\mathrm{pH}$ values from 3 to 9 (Hikino and Farnsworth, 1985).

Stevia is recommended for diabetic patients because it is non-calorie sweetener and is approved by the Food and Drug Administration (FDA) as a dietary supplement (Bespalhok and Hattori Filho, 1997). The powdered form of stevia leaves possessed both hypoglycemic and body weight reducing effect without any adverse effects for diabetic patients(Summon et al., 2008). Stevia leaf extract has the ability to reduce the blood sugar level up to $35.2 \%$ within 6 to $8 \mathrm{~h}$ of ingestion (Oviedo, 1971). Stevia also can act as an antimicrobial in pharmacological studies and according to (Debnath, 2008), the crude leaf chloroform extract of $S$. rebaudiana leaves can inhibit Staphylococcus aureus, Streptococcus mutans, Bacillus subtilis and Escherichia coli. The largescale cultivation of stevia plants is important for the human health because of the above benefits and no allergic reactions seem to exist (Geuns, 2013).

The conventional methods of cultivation or propagation of Stevia is time consuming, unpredictable, unreliable and less productive. Propagation of $S$. rebaudiana is done by seeds and stem cuttings. The main problem involved in commercial cultivation of this species is its heterozygous and self-incompatible nature, which leads to the poor fertilization (Miyazaki and Wantenabe, 1974). Stevia seeds show very low vigor and germination and further, heterozygosis leads to high variability in sweetening levels and composition (Miyagawa, 1986). Vegetative propagation is also limited by the low number of propagules obtained from a single plant and destruction of the mother plant to obtain cuttings. Therefore, there is a crucial need to develop methods for rapid multiplication of Stevia and to overcome these problems, in vitro culture techniques can be applied for mass propagation and the production of homogenous plants of $S$. rebaudiana. Thus, the present study was focused on the development of an efficient protocol for in vitro propagation of $S$. rebaudiana for mass scale plant production for commercial cultivations.

\section{Materials and methods}

\section{Explants and surface sterilization}

Shoot tips and nodal explants were collected from healthy shoots of Stevia rebaudiana, growing in the shade house condition. The excised shoot tips and nodal explants were washed thoroughly with $5 \%$ teepol $\left(\right.$ Teepol $^{\mathrm{TM})}$ for 8 - 10 minutes and then, under running tap water for 30 minutes. Thereafter, the explants were surface sterilized in $15 \%$ Clorox solution for 5 minutes followed by 3-4 washes with sterile distilled water.

\section{Culture conditions}

The sterilized single nodal and shoot tip explants were cultured on hormone free MS (Murashige and Skoog, 1962) basal medium with $30 \mathrm{~g} \mathrm{~L}^{-1}$ of sucrose and solidified using $7.5 \mathrm{~g} \mathrm{~L}^{-1}$ of agar for culture establishment. The $\mathrm{pH}$ of the medium was adjusted between 5.6 and 5.8 before autoclaving at $1.5 \mathrm{Kgcm}^{-2}$ at $121^{\circ} \mathrm{C}$ for 20 minutes. Cultures after inoculation were incubated at $25 \pm 2{ }^{\circ} \mathrm{C}$ and $65-$ $70 \%$ relative humidity with photoperiod $16 \mathrm{~h}$ light and $8 \mathrm{~h}$ dark with 3000 lux light intensity by florescent tubes.

\section{Shoot and root induction}

For shoot induction and multiplication, the established cultures were transferred to MS medium supplemented with various combinations and concentrations of kinetin and BAP (6-benzylamino purine) with constant level of NAA (1-naphthalene acetic acid) as shown below (Table 1).

The regenerated isolated shoots were used as explants for root induction. Micro-shoots of about $2-3 \mathrm{~cm}$ in length were excised and inoculated on MS medium with IAA $(0.2(\mathrm{mg} / \mathrm{L}))$ and two levels of IBA $(0.2,0.5(\mathrm{mg} / \mathrm{L}))$. The MS medium without any hormones (MS0) was used as the control. 


\section{Acclimatization}

Rooted plantlets grown on the MS medium supplemented with IBA and IAA were taken out from the culture vessels and their roots were carefully washed with distilled water. Then, the rooted plantlets were washed with lukewarm water and dipped in a fungicide solution for 10 minutes. Plantlets were transferred to coco-pellets $(32 \mathrm{~mm})$ and poly bags filled with a mixture (1:1) of sterilized coir dust and compost. The plantlets were covered with transparent polythene and placed in the growth room at $28 \pm 2{ }^{\circ} \mathrm{C}$ with $90-100 \%$ humidity for three weeks. The transparent polythene cover was opened and the plantlets were gradually exposed to the ambient room temperature. After that, the plantlets were transferred to the nursery and placed under shade for four weeks to avoid direct sunlight before field planting.

\section{Data Collection and Analysis}

All experiments were arranged as Completely Randomized Design (CRD) with 20 replicates and data were statistically analyzed. Various growth data were recorded such as the number of multiple shoot formation, shoot length, number of roots, root length, and survival of plants during acclimatization. Mean separation was done with DMRT (Duncan's Multiple Range Test).

\section{Results}

\section{Multiple Shoot Induction}

Slightly tender nodal explants of medium thickness $(0.3-0.5 \mathrm{~cm})$ with emerging greenish axillary buds responded more favorably in terms of bud sprouting and shoot differentiation. The survival percentage and their subsequent development into shoots varied from 40-80\% in nodal and shoot tip explants on MS medium supplemented with various plant growth regulators and concentrations (Fig. 1).

To obtain plantlets with uniform growth characteristics of the mother plant, the direct regeneration is essential. Nodal explants are suitable for a large-scale production and multiple shoots can easily be obtained in vitro from this explant type (Karim et al., 2013). On average, 2025 buds regenerated from nodal segments and 1014 shoot buds regenerated from shoot tip explants in MS medium with $1.0 \mathrm{mg} / \mathrm{L}$ of Kinetin either with $0.5 \mathrm{mg} / \mathrm{L}$ or $1.0 \mathrm{mg} / \mathrm{L}$ of BAP (Fig. 2). Since, there was no significant difference $(p>0.05)$ between bud regeneration from nodal explants in MS medium with varying BAP levels $(0.5 \mathrm{mg} / \mathrm{L}$ and $1.0 \mathrm{mg} / \mathrm{L})+1 \mathrm{mg} / \mathrm{L}$ Kinetin, for commercial production $0.5 \mathrm{mg} / \mathrm{L} \mathrm{BAP}+1 \mathrm{mg} / \mathrm{L}$ Kinetin in presence of $0.2 \mathrm{mg} / \mathrm{L}$ NAA can be recommended. The lateral buds were developed into shoots after 30 days of incubation. Different combinations and concentrations of BAP and Kinetin were used on MS medium for optimizing multiple shoot regeneration.BAP containing media were found to be more effective than Kinetin and TDZ containing media with regard to the shoot multiplication as observed in other micropropagation studies of $S$. rebaudiana (Sivaram and Mukundan, 2003; Thiyagarajan and Venkatachalam, 2012). On the contrary, our study showed that combination of both BAP and Kinetin provides a synergistic effect on shoot multiplication of $S$. rebaudiana shoot tips and nodal explants. According to our observations (Fig. 3), best response in terms of multiple shoot regeneration was observed on MS medium supplemented with $0.2 \mathrm{mg} / \mathrm{l} \mathrm{NAA}+0.5 \mathrm{mg} / \mathrm{l} \mathrm{BAP}$ $+1 \mathrm{mg} / \mathrm{l} \mathrm{kin}$ and $0.2 \mathrm{mg} / \mathrm{l} \mathrm{NAA}+1 \mathrm{mg} / \mathrm{l} \mathrm{BAP}+1$ $\mathrm{mg} / \mathrm{l}$ kin resulting 24 and 20 shoots/ex plants in one sub culture (within 6 weeks after inoculation) but economical point of view $0.2 \mathrm{mg} / \mathrm{l} \mathrm{NAA}+0.5$ $\mathrm{mg} / \mathrm{l} \mathrm{BAP}+1 \mathrm{mg} / \mathrm{l} \mathrm{kin}$ is suitable for commercial production. The highest frequency $(94.50 \%)$ of multiple shoot regeneration with maximum number of shoots (15.69 shoots/explant) was noticed on MS medium supplemented with $1.0 \mathrm{mg} / \mathrm{l}$ BAP (Thiyagarajan and Venkatachalam, 2012). The same authors, Thiyagarajan and Venkatachalam (2012) have stated that, for large scale plant production, in vitro derived nodal bud explants were cultured on MS medium fortified with 1.0 $\mathrm{mg} / \mathrm{l} \mathrm{BAP,} \mathrm{in} \mathrm{which} \mathrm{about} 123$ shoots/explant were obtained after three subcultures on the same media composition. 
Table 1. Different levels of BAP and Kinetin used for shoot proliferation.

\begin{tabular}{llllll}
\hline NAA $(\mathbf{m g} / \mathbf{L})$ & BAP $(\mathbf{m g} / \mathbf{L})$ & Kinetin $(\mathbf{m g} / \mathbf{L})$ & NAA $(\mathbf{m g} / \mathbf{L})$ & BAP $(\mathbf{m g} / \mathbf{L})$ & Kinetin $(\mathbf{m g} / \mathbf{L})$ \\
\hline 0.2 & 0.5 & 0 & 0.2 & 1 & 0 \\
0.2 & 0.5 & 0.5 & 0.2 & 1 & 0.5 \\
0.2 & 0.5 & 1.0 & 0.2 & 1 & 1.0 \\
0.2 & 0.5 & 2.0 & 0.2 & 1 & 2.0 \\
\hline
\end{tabular}
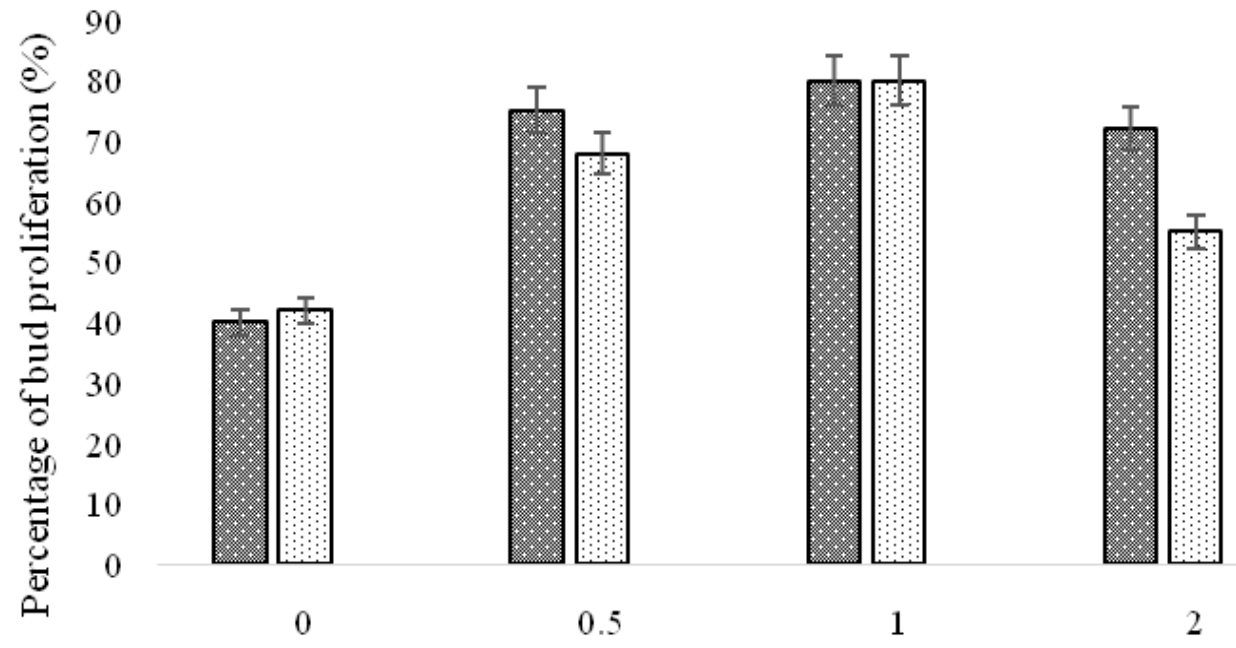

Kinetin (mg/L)

Fig. 1: The percentage of bud breaking and their subsequent development into shoots of Stevia rebaudiana with different BAP and KIN on MS medium.

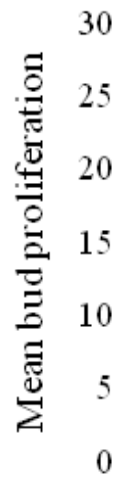

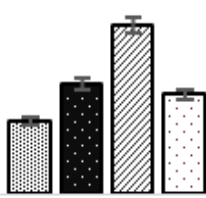

Shoot tips

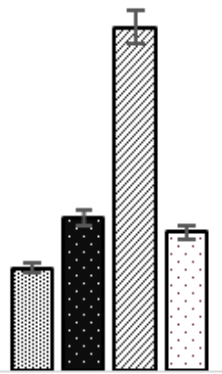

Nodes

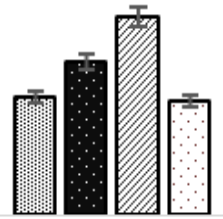

Shoot tips

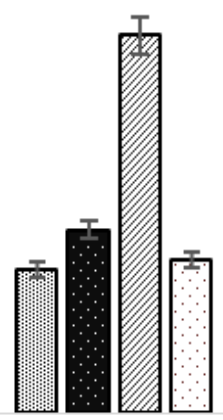

Nodes

$\mathrm{BAP}(0.5 \mathrm{mg} / \mathrm{L})$

$\operatorname{BAP}(1.0 \mathrm{mg} / \mathrm{L})$

Kinetin (mg/L)

阐 00

Fig. 2: Mean bud proliferation of shoot tips and nodal explants in different BAP and kinetin levels. 


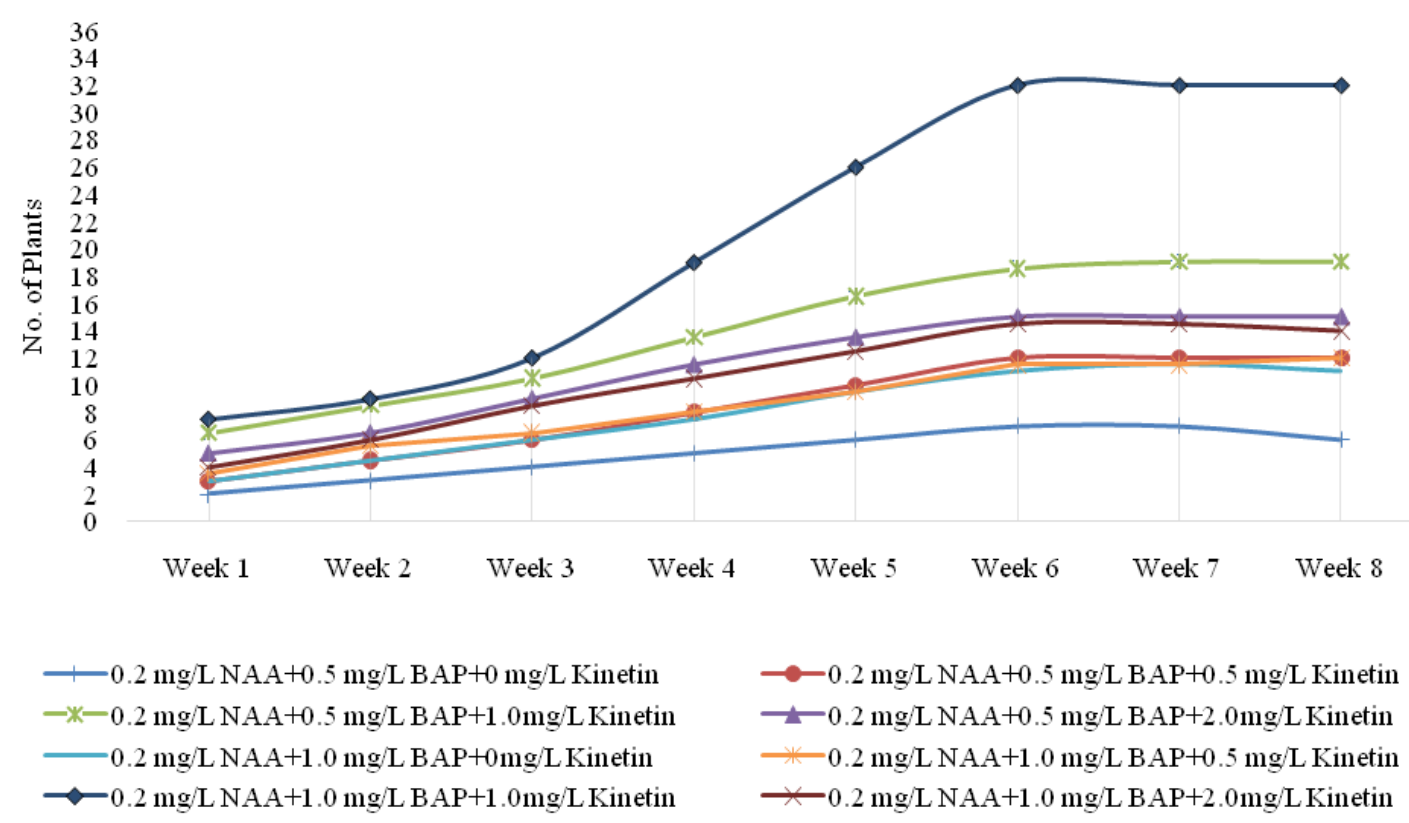

Fig. 3: Plantlet proliferation rate of Stevia rebaudiana.

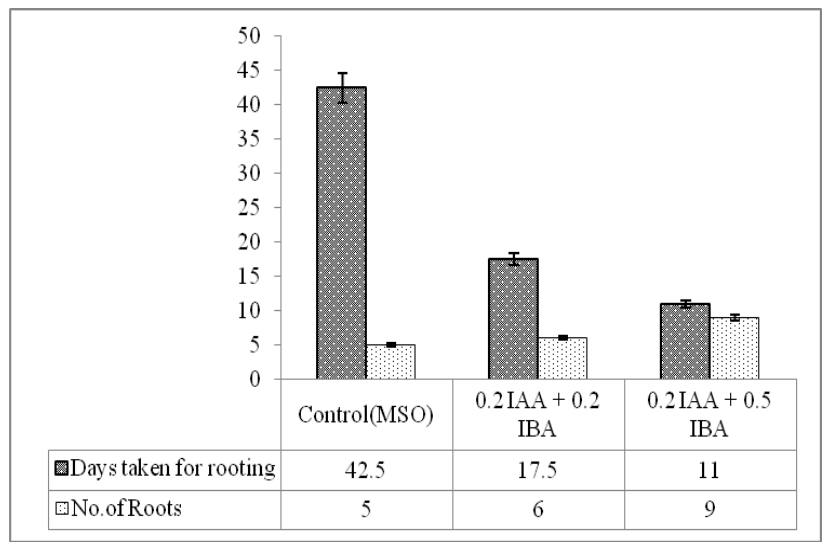

Fig. 4: Number of roots and days taken for rooting of Stevia rebaudiana.

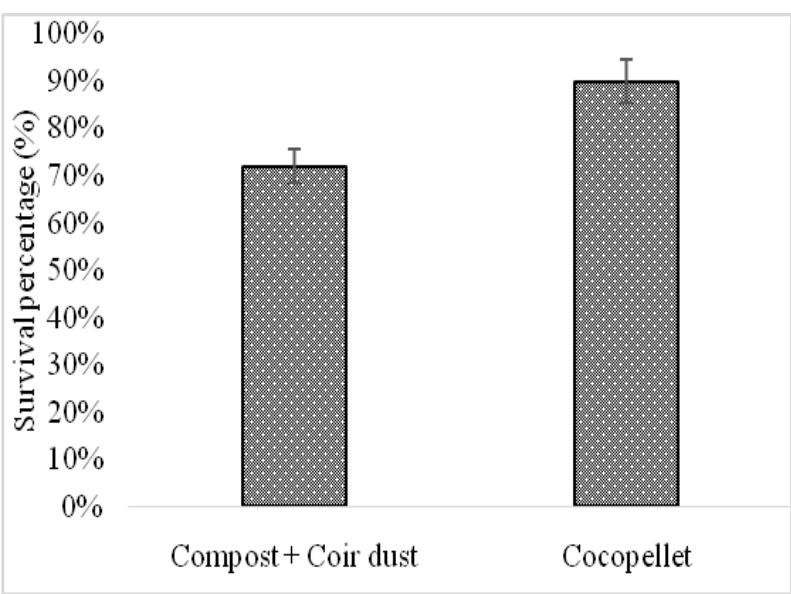

Fig. 5: Survival percentage of Stevia rebaudiana.
In commercial cultivation, production of a large number of plantlets within a minimum time duration is essential (Cristiano et al., 2016). In this study, it was observed that by $6^{\text {th }}$ week after culture initiation, nodal ex plants give rise to maximum number of shoots with high vigor and the trend was continued (Fig. 3). Repeated subculture is usually applied for increasing the shoot bud multiplication rate. Use of repeated subculture technique to increase the number of shoot buds in Ptertocarpus santalinus has increased in shoot bud multiplication rate up to the six-subculture stage (Prakash et al., 2006).

\section{Root induction}

Highest number of roots (6-8) was observed in MS medium supplemented with $0.5 \mathrm{mg} \mathrm{L}^{-1}$ of IBA and $0.2 \mathrm{mg} \mathrm{L}^{-1}$ IAA10-12 days after inoculation (Fig. 4). According to Yucesan et al. (2016), IAA was more effective for root formation, producing 7.6 roots per shoot with $100 \%$ rooting frequency. Similar result was also obtained from $1.0 \mathrm{mgL}^{-1} \mathrm{NAA}$ (RockOkuyucu, 2016). The root development was recorded on MS0 without adding auxin 40-45 days after inoculation. The plantlets with well-developed shoots and roots were transferred to coco-pellets and poly bags for acclimatization. 

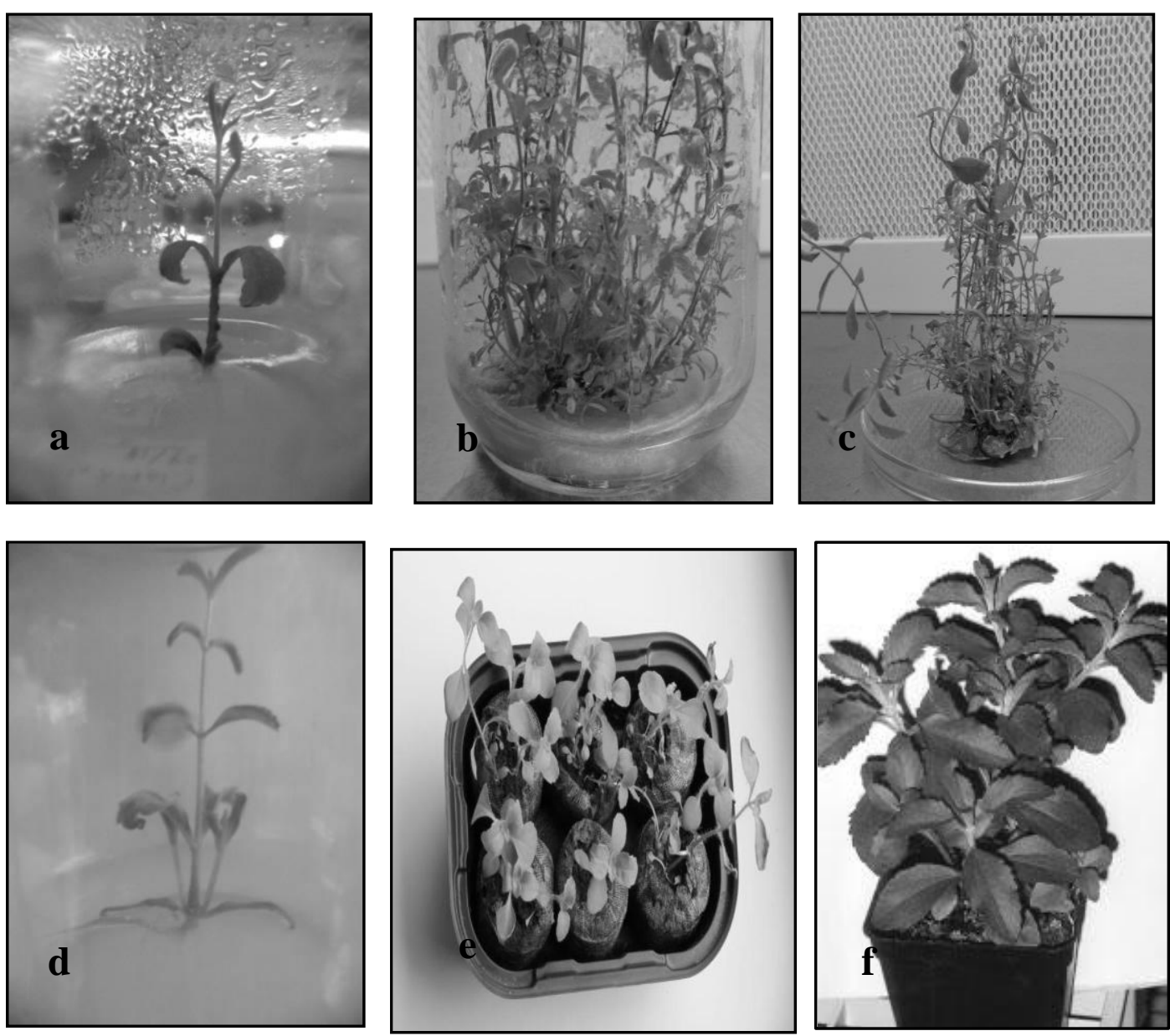

Fig. 6: In vitro propagation of Stevia rebaudiana using shoot tip and nodal explants: a: growth of shoot tip explant, b, c: proliferated plants of Stevia, , d:Rooted planets; e, f: acclimatized plants in coco-pellets and pots.

\section{Acclimatization}

Highest survival percentage $(90 \%)$ was observed in coco-pellet as substrate and maintaining under high humid conditions for 2-3 weeks (Fig. 5). Cocopellets have good air porosity, water retention and are environmentally friendly. These pellets make the plantlets grow with stronger and more fibrous roots due its high water retaining capacity and airfilled porosity. Regenerated plants grew well and phenotypically similar to the parental stock.

\section{Conclusion}

This study provides an efficient in vitro propagation method that could be commercially feasible for Stevia rebaudiana Bertoni using a simple and costeffective protocol for producing true to type plants in a relatively short period and with high multiplication rate. This protocol can be utilized for commercial scale propagation and conservation of this valuable plant species.

\section{Acknowledgement}

The support and guidance received from $\mathrm{Mr}$. HKMS Kumarasinghe, Department of Crop Science, Faculty of Agriculture, University of Ruhuna, Sri Lanka is highly acknowledged.

\section{References}

BespalhokJC, Hattori Filho K 1997. Embryogenic callus formation and histological studies from Stevia rebaudiana (Bert.) Bertoni floret explants. Rev. Bras. Fisiol. Veg. 9, 185-188. 
Bhosle, S., 2004. Commercial cultivation of Stevia rebaudiana. Agrobios Newsl. 3(2), 43-45.

Cristiano, G., Murillo-Amador, B., De Lucia, B., 2016. Propagation techniques and agronomic requirements for the cultivation of Barbados aloe (Aloe vera (L.) Burm. F.) -A review. Front. Plant Sci. 7, 1410.

Debnath, M., 2008. Clonal propagation and antimicrobial activity of an endemic medicinal plant Stevia rebaudiana. J. Med. Plants Res. 2, 45-51.

Hikino, H., Farnsworth, N. R. (Eds.), 1985. Wagner Economic and Medical Plant Research: Current Status of Stevioside as a Sweetening Agent for Human Use. Academic Press, London.

Karim, M., Jannat, R., Rahman, M., Haque, M., 2013. Micropropagation of Stevia plant from nodal segments. Progress. Agric. 19, 20-28.

Miyagawa, H.N., Fujioka, H., Kohda, K., Yamasaki, K., Taniguchi, Tanaka, R., 1986. Studies on the tissue culture of Stevia rebaudiana and its components. Induction of shoot primordia. Planta Med. 52, 321-323.

Miyazaki, Y., Wantenabe, H., 1974. Studies on the cultivation of Stevia: On the propagation of plant. Jap. J. Trop. Agric. 17, 154-157.

Oviedo, C.A., 1971. Accionhipoglicemiante de la Stevia rebaudiana Bertoni (kaa-he-e). Excerpta Medica. 208, 92-93.

Prakash, E., Sha Valli Khan, P.S., Sreenivasa Rao, T.J.V., Meru, E. S., 2006. Micropropagation of red sanders (Pterocarpus santalinus L.) using mature nodal explants. J. For. Res. 11, 329-335.
Rock-Okuyucu, B., Bayraktar, M., Akgun, I., Gurel, A., 2016. Plant growth regulator effects on in vitro propagation and stevioside production in Stevia rebaudiana Bertoni. HortScience. 51(12), 1573-1580.

Sivaram, L., Mukundan, U., 2003. In vitro culture studies on Stevia rebaudiana. In Vitro Cell. Dev. Biol. Plant. 39, 520-523.

Soejarto, D.D., Kinghorn, A.D., Farnsworth, N.R., 1982. Potential sweetening agents of plant origin. III. Organoleptic evaluation of Stevia leaf herbarium samples for sweetness. J. Nat. Prod. 45(4), 590-595.

Summon, M.H., Mostofa, M., Jahan, M.S., Kayesh, M.E.H., Haque, M.A., 2008. Comparative efficacy of powdered form of Stevia (Stevia rebaudiana Bertoni) leaves and glimepiride in induced diabetic rats. Bangl. J. Vet. Med. 6(2), 211-215.

Tanaka, O., 1982. Steviol-glycosides: New natural sweeteners. Trend. Anal. Chem. 1, 246-248.

Thiyagarajan, M., Venkatachalam, P., 2012. Large scale in vitro propagation of Stevia rebaudiana (Bert) for commercial application: Pharmaceutically important and antidiabetic medicinal herb. Indust. Crops Prod. 37(1), 111117.

Yucesan, B., Mohammed, A., Buyukgoçmen, R., Altug, C., Kavas, O., Gurel, S., Gure, El., 2016. In vitro and ex vitro propagation of Stevia rebaudiana Bertoni with high Rebaudioside-A content-A commercial scale application. Sci. Hortic. 203, 20-28.

\section{How to cite this article:}

Fonseka, D.L.C.K., Wickramaarachchi, W.W.U.I., Aluthgamage, H.N., 2018. Mass production of Stevia rebaudiana (Bertoni) Bertoni for commercial cultivation. Int. J. Curr. Res. Biosci. Plant Biol. 5(6), 45-51. doi: https://doi.org/10.20546/ijcrbp.2018.506.004 